\title{
Mechanical Shock Problem
}

National Cancer Institute

\section{Source}

National Cancer Institute. Mechanical Shock Problem. NCI Thesaurus. Code C92080.

Problems caused by the sudden violent blow or collision to the whole device (e.g. by dropping). 